\title{
ОБРАЗОВАНИЕ КАК КАНАЛ ТРАНСЛЯЦИИ НРАВСТВЕННЫХ ЦЕННОСТЕЙ СОЦИУМА
}

\section{О.П. Пунченко, П.Е. Козленко}

Каждый этап в развитии познания характеризуется особым комплексом проблем, образующих в своей совокупности интеллектуальный горизонт соответствующего уровня развития социума. Одни из этих проблем впоследствии, в силу развития философского научного знания, обнаруживают свой преходящей характер, другие же с той или иной степенью достоверности и обоснованности входят в структуру теоретического мышления любого времени. Их разработка является необходимостью, поскольку они отображают в своем содержании и процесс познания человеком природы, и взаимоотношения людей во всех сферах деятельности.

Одной из таких проблем является исследование образования как ценностного критерия социального бытия человека, как смыслообразующего императива духовной культуры социума. Многоаспектность и многовекторность исследования образования подтверждает старое, но вечно актуальное утверждение, что нельзя испортить социум избытком образования и нравственности.

Целью данной статьи выступает: во-первых, раскрытие образования как одного из стратегических каналов трансляции духовных ценностей социума; во-вторых, объяснение на основе параметрической общей теории систем концепта, структуры и субстрата системы образования.

Становление философии образования как относительно самостоятельного направления в социальной философии объясняется рядом причин. Во-первых, на наш взгляд, отсутствует необходимая дисциплинарная строгость и системность в объяснении предмета, методоло-

Актуальні проблеми духовності

(Відп. ред.: Я.В. Шрамко)

Кривий Ріг (2007), 215-224 
гии, стратегии и тактики образования. Многие философские категории, такие как общее-особенное-единичное, сущность и явление, содержание и форма и другие допускают неоднозначность толкования своего содержания и диалектической взаимосвязи в рамках отдельных исследований. Поэтому необходимо преодоление этой сложившейся метафизичности в объяснении сущности образования и превращение его в строгую, сложную специализированную систему, имеющую свои собственные закономерности функционирования и развития. Философия образования призвана произвести экспликацию, «распредмечивание» классического предмета образования и обеспечить выход на новые образовательные ценности, новые нравственные ценностно-смысловые принципы.

Во-вторых, поиск социальной философией собственной «ниши» в исследовании образования потребовал четкого понимания и объяснения смыслового поля образования, его смысловых акцентов, а также универсализации образования, вызванной к жизни потребностями личности в постоянном обновлении знаний в условиях возрастающего динамизма духовного производства.

В-третьих, необходим четкий методологический анализ инфраструктуры образования. Здесь необходимо задействовать, по возможности, весь арсенал эмпирических и теоретических методов, а также форм научного познания. Анализ образования в педагогике, лингвистике, социологии и других дисциплинах показывает, что философская методологическая база здесь не всегда используется объективно и эффективно, а что касается оснований параметрической общей теории систем, с позиций которой можно четко объяснить концепт, структуру и субстрат образования на основе атрибутивных и реляционных параметров, то такого исследования содержания образования не обнаруживается ни в одной дисциплине.

В-четвертых, в связи с переходом Украины к построению информационного общества, необходимо не только теоретическое объяснение сущности единого образовательного пространства, но и раскрытие последнего как уникальной формы социального бытия интеллектуальной собственности человечества. Но поскольку все природные и социальные процессы рассматриваются через призму единства пространства и времени, то задачей философии выступает и исследование временной составляющей инфрастуктуры образования, включающей информационное, коммуникативное и дисциплинарное время.

В-пятых, усилившееся в последние годы ощущение стагнации образования, выражающееся в неудовлетворенности его результатами, а 
также в консервативности образовательной системы, не имеющей финансовых возможностей и не всегда желающей учитывать динамизм общественной жизни, привело к выхолащиванию ценностно-нравственного, смыслообразующего стержня системы образования, что отразилось в разрыве между уровнем подготовки специалистов и потребностями общества.

Вышеотмеченные моменты и требуют общефилософского анализа образования и такого его ценностно-смыслового модуса как нравственность.

Образование - один из оптимальных и интенсивных каналов вхождения человека в мир культуры, которая выражает меру его развития, меру цивилизованности. Именно в процессе образования человек осваивает культурные ценности, образцы поведения и деятельности, а также устоявшиеся формы общественных отношений, обретает социокультурные нормы. Применительно к образованию человека, культура - это процесс культивирования духовных способностей человека, атрибутивных свойств Homo Sapiens, таких, как стремление разума к познанию, деятельности, свободе, самоутверждение и склонность оценивать себя с позиций полезности обществу.

Процесс образования как усвоение человеком новых культурных научных ценностей в рамках общего его духовного развития является по характеру и содержанию творческим, поскольку этот процесс отражает практику социализации человека и преемственности поколений. В разных социально-политических условиях образование выступает стабилизирующим фактором между новыми социальными представлениями и идеалами предшествующих поколений, способствует адаптации человека к новым жизненным условиям. Сохранение преемственности культурно-образовательной традиции и самобытности сложившихся систем ценностей способствует их интеграции в системе мировых ценностей как элементов макросоциума. Жизнь человека представляется звеном в цепи поколений, то есть человек живет в пространстве социокультурной традиции, которая оказывает существенное влияние на формирование его характера, стиля поведения, устремлений, ценностей и интересов. В связи с этим отношения между традицией и новациями в сфере образования человека воплощают взаимосвязь между образованием и культурой народа в целом.

Если обратиться к схеме воспроизводства культуры и деятельности, предложенной еще в 60-х гг. ХХ века в рамках общей теории деятельности, то в ней различаются трансляции культуры, т.е. культурных норм, и социума, т.е. реальной жизни. В историческом отрезке 
времени переход одного состояния социума в другое не происходит непосредственно, оно всегда идет через культуру, через особую связь, через отношение нормы и ее реализации. Если бы реализация культурных норм, транслируемых во времени, осуществлялась по готовым схемам, через готовые модели и при помощи готовых механизмов, то цивилизация давно бы себя исчерпала.

Образование - один из самых действенных и эффективных каналов реализации культурных норм, но не при помощи готовых механизмов и не в виде одиночных актов отношения нормы к реальному действию в ограниченном рамками культурном контексте. Чтобы образование действительно обеспечивало полный цикл воспроизводства культуры и деятельности, оно должно включить в себя весь механизм такого воспроизводства, т.е. нужно обязательно вернуться в прошлое, внимательно посмотреть на настоящее, максимально точно представить будущее. Причем под возвращением в прошлое следует понимать не событийную историю, а историю того, как и с какими последствиями входили в культуру те или иные новации, сколь долго они существовали, каким образом транслировались и реализовывались на фоне меняющихся условий ${ }^{1}$.

Образование как социально-ценностный процесс, отражающий меру развития человека и общества, представляет собой специфическую систему субъект-субъектных отношений, в которой осуществляется трансляция новейших для субъекта теоретических представлений о сущности и закономерностях развития природной и социальной действительности, усвоение этих знаний познающим субъектом и развитие последним методологии преобразования этой действительности. Именно такое понимание образования как целенаправленного процесса передачи знаний, основанного на новой методологии их трансляции и накопления, связано с глубоким теоретическим их осмыслением, пониманием и усвоением, что в целом и отличает теоретические конструкты образования, их парадигмы развития, от того способа приобретения знаний, который характерен для обыденного уровня познания.

Если в структуре обыденного познания в приобретении знаний господствует стихийность, случайность, применяются несистематизированные практические приемы их получения, то на теоретическом уровне образование носит необходимый, планомерный и закономерный характер, что связано с новыми способами получения знаний - специ-

\footnotetext{
${ }^{1}$ Но при этом необходимо учитывать, что в истории человечества имели и имеют место и другие каналы трансляции норм духовной культуры, например, искусство, литература и т. д.
} 
ально выработанными приемами, составляющими в совокупности методологию образования. Освоение нового систематизированного знания и выступает непосредственной целью образования. Конечной же его задачей является эффективное использование субъектом достигнутых знаний в ходе практического преобразования природной и социальной действительности.

Образование, применительно к социуму, - это действительно процесс «космического масштаба». Оно создает условия для поднятия сознания личности до высших атрибутов духовной экзистенции - справедливости, свободы, чести, совести, доброты, верности идеалам, толерантности. Именно здесь обнаруживается их духовность со всеми высокогуманными ее атрибутами. И если согласиться с Гегелем, что «бытие человека есть его действие», то именно по характеру современного образования необходимо судить о состоянии духовности социума.

Сфера образования - особый тип реальности, где специфически проявляются объективная детерминация и субъективные интенции, потребности и интересы, экзистенциалы и ценности, нормы и своеволие, рациональность и иррациональность, традиции и новации, стереотипы и прозрения, «просвещенное своекорыстие» и общечеловеческие идеалы, явления психики и постулаты идеологии. Это сфера взаимодополнения и противоборства, критики и взаимоотторжения, сомнений и верований, убеждений и отчаяния, четкости логики и смутности интуиции, ясных целей и архетипов, политических программ и личностных решений, философских взглядов и эзотерических поисков, нравственных императивов и морального нигилизма. В подобном ментальном хаосе образовательной реальности только и может сложиться, установиться и воспроизводиться совокупность реалий, именуемых духовной синергией. Духовная синергия образования - это информационно-коммуникационная структура жизни общества, совокупность побуждений к адекватному поведению человека в социуме.

Снижение возможности получения качественного образования и спад обретения фундаментальных основ в школе - это спонтанно нарастающий процесс его деинтеллектуализации, декультуризации, десоциализации, нравственной деградации, усиления нигилизма. Парадокс здесь заключается в том, что к началу третьего тысячелетия с его неисчерпаемым потенциалом технического прогресса образование сталкивается с реальными перспективами своего метафизического (одностороннего) развития, что и подтверждается отношением сегодня к информационно-коммуникационным технологиям, трансляция содержания которых выступает в качестве необходимой установки 
управляющих структур образования, а это - новый вариант технократизма.

Тем не менее, духовная синергия в образовании обнаруживает и положительную ее составляющую, позволяющую в существенной мере избежать пессимистических выводов в оценке перспектив его развития. Это линия гуманизации образования и человека. Она стихийно проявлялась в общественных отношениях, образовании и интеракциях людей на протяжении всей истории и закреплялась в нормах морали, права, культуры. Известны концептуально оформленные исторические версии гуманизма - романтическая, религиозная, интеллектуальная и др. Но в структуре современной образовательной синергии не может быть признано нормальным дискретное и спонтанное обращение к идее гуманизма. Эту идею сознательно и целеустремленно противопоставляют сейчас технократическим идеям, в которых гуманизм играет роль невостребованого довеска. Но становление информационной цивилизации требует и формирования научного знания на основе практически действенного гуманизма. Поэтому новая парадигма образования - информационно-преобразовательная, требует осмысления своего содержания как отражение развития духовной синергии будущего общества.

Анализ образования как жизненного феномена духовного производства требует и своего системно-структурного анализа, раскрывающего его богатство не только как гносеологического атрибута, но и «как целостного явления, обладающего своей специфической универсальностью и необходимостью. Системный подход тсходит из того, что специфика сложного объекта ... коренится прежде всего в характере связей и отношений между определенными элементами» $[1$, с. 168].

Системный анализ философии образования позволяет выстроить конструкции образовательного пространства в разных его аспектах. Это - онтологический аспект: исследование сущности и содержания образовательного процесса в контексте социального бытия, анализ различных элементов системы образования, их взаимодействия между собой и с окружающей средой. Гносеологический аспект: использование законов и принципов познания для теоретического, рационального, нравственного отражения системы образования в современной теории познания. Праксеологический аспект: пути преобразования и оптимизации образовательной системы, современной образовательной практики. Аксиологический аспект: определение главных ценностей системы образования, духовно-нравственных ориентиров теории и практики образовательного процесса. Мировоззренческий аспект: 
формирование жизненных ориентиров в процессе образования. Несомненно, что этот аспект является синтезирующим.

Но системный анализ образования совершенно немыслим без методологического аспекта. Здесь в нем можно выделить двойственную природу. С одной стороны, образовательный процесс невозможен без определенной методологии трансляции и усвоения знаний: они были присущи и восточному традиционализму, и греческой пайдее, и христианскому образованию, и универсальной образованности как идеалу эпохи Просвещения, и классическому идеалу образованности в эпоху «переоценки ценностей», и современному этапу, характеризующемуся информатизацией образования и его гуманитаризацией. С развитием познания и образования дополнялась методология приобретения знаний. Сегодня она включает в себя и всеобщий метод познания - диалектику, и методы эмпирического и теоретического познания, и формы научного знания. Но эти методы и формы используются как средства получения информации, прежде всего, на пути познания истины.

С другой стороны, методология требует и внутреннего системного анализа самой категории «образование». Системность в философии образования необходимо понимать в широком всеобъемлющем аспекте, как метатеорию и метапрактику образования.

Применение системного метода к анализу образования имеет свои особенности, которые заключаются в том, что этот теоретический метод, в объяснении образования неразрывно связан с такой формой познания как конструктивная философская критика. Системный метод - это способ теоретического преобразования реалий бытия, а «философская критика как специфически-познавательная и социальноценностная процедура углубляет момент критического мышления об этих реалиях» [2, с.9-10].

Во взаимосвязи системного метода и конструктивной философской критики можно раскрыть устойчивое и изменчивое в образовании, сущностные характеристики последнего. В то же время, системный метод «должен быть однороден объекту его приложения, - отмечает Цофнас А.Ю., - . . он должен иметь специфические способы получения и обоснования знания, другие средства представления результата, чем это имеет место в объекте, к анализу которого его применяют» $[5$, c. 36]. Применительно к нашему исследованию можно сказать, что философским рассуждениям об образовании будет соответствовать такая из теорий систем, которая способна описывать единичные вещи в образовании не с точки зрения их отношения к общему, а именно в соответствии с тем, что понятие образования рассматривается нами 
как интенциональное и имеет средства анализа, выходящие за пределы чисто интуитивного характера постижения. Обоим этим условиям соответствует параметрическая общая теория систем, которая исходит из того, что главное - это специфические системные свойства (т. е. параметры), вернее связи этих параметров.

Исследуя систему, под которой понимается любой объект познания, представленный в триаде «вещь-свойство-отношение», Уемов А.И. выделяет три ее неотъемлемых компонента: концепт, структуру, субстрат, которые объединены общим понятием «дескрипторы». Используя эту методологию объяснения сущности системы, проанализируем образование как гносеологический феномен, с учетом классификации системных параметров, которые современная теория систем разделяет на атрибутивные и реляционные. Эти значения определяются при соотнесении систем друг с другом и в единстве названных параметров раскрывается сущность параметрической модели теоретизирования. Классификации этих параметров широко представлены в философских исследованиях Урманцева Ю.А., Сагатовского В.Н., Богдановича В.И., Сараевой И.Н. и Коздобы А.Л., Уемова А.И.

Согласно классификации Уемова А.И., основными атрибутивными параметрами системы выступают «расчлененность, завершенность, имманентность, минимальность, центрированность, детерминированность, стационарность, стабильность, надежность, регенеративность, вариативность, однородность, валидность (сила), автономность, уникальность» [3, с. 56-57]. Характеризуя перечисленные параметры, авторы работы [3], выделяют цепные и нецепные, индивидуальные, инерционные и ресурсные, а также окрытые системы. Нас интересуют открытые системы, потому что образование выступает именно такой, динамично взаимодействующей с внешней средой системой.

Использование системного подхода в ракурсе параметрической общей теории систем предполагает определение основных ее понятий субстрата, структуры и концепта [4, с. 123]. Если «системой является любой объект, в котором имеет место какое-то отношение, обладающее заранее определенным свойством» [4, с. 120], то в качестве «концепта» выступает определенное свойство, заранее предполагаемый смысл, заранее известные субъекту цели, какая-то исходная информация, существующая для системного представления объекта, на которую познающий субъект опирается. Структура представляет собой системообразующее отношение, соответствующее принятому концепту. Субстрат же - это сама вещь, представляемая в виде системы, в частности ее элементы. 
Как же понимается этот метод в исследовании образования? Глобальной системой здесь выступает само образование как модус духовного производства. Однако, внутри этой системы можно выделить подсистемы, связанные со сменой парадигм образования: подсистема содержания этого процесса, включающая процесс развития и обновления знаний и представлений человека об окружающей природной и социальной действительности; совершенствование трансляции знаний (подсистема методико-методологического плана); подсистема формирования мировоззренческих установок у обучаемого (целевой аспект) и другие.

Основным отношением в образовании выступает процесс взаимосвязи обучающего и обучаемого, раскрывающийся в объяснении, понимании и усвоении определенных знаний. В качестве концепта здесь выступает необходимость познания человечеством основных законов и закономерностей развития природы и общества и на основе этих знаний - прогнозирование дальнейшего их бытия. Структура образования как системообразующее отношение включает в свое содержание классификацию наук, их взаимосвязь и взаимодополняемость. Элементами же образовательной системы, составляющими ее субстрат, являются как организационные элементы-министерство образования, вуз, деканаты, кафедры, так и содержательные - квалификация преподавательского состава, циклы дисциплин, последовательность их изучения, отчетность студентов, наличие материальной базы в вузе и многое другое.

Системный анализ как метод познания строго последователен: здесь мы движемся от концепта $-P$, к структуре $-R$, а затем к субстрату $-m:(P \rightarrow R \rightarrow m)$. Эта последовательность раскрывает элементную базу системы, ее свойства, которые имеют значение атрибутивных системных параметров. Выше были отмечены эти параметры, но нас интересует прежде всего целостность образования как социокультурного феномена и его уникальность среди других феноменов системы духовного производства. Целостность и уникальность в своем качестве абсолютно равноправны. Целостность - это не точечное свойство (т. е. такое, которое может либо быть, либо отсутствовать), а линейное - оно изменяется по степеням, «причем эти степени допускают, - как считает Цофнас А.Ю., - не количественную оценку, что особенно важно при анализе историко-культурных ценностей» $[5$, с. $117-$ 119].

Но если целостное в образовании можно ранжировать по степеням, то уникальное - ни в коем случае, вопрос о степени уникальности бес- 
смыслен. Например, и англо-американская, и российская, и Болонская системы образования уникальны в том плане, что они неповторимы, не дублируют одна другую, но говорить о предельной степени уникальности одной из них - это нонсенс. Анализ уникальности позволяет утверждать, что она может быть концептуальной, структурной, элементной и т. д. Но можно ли говорить о возможной предельной степени уникальности образования как целостной системы? Она может быть, независимо от субъективных оценок, уникальной не по одному из дескрипторов (по концепту, структуре или элементам), а сразу по двум или трем из них. Предельная степень уникальности системы образования - это ее уникальность сразу по всем трем дескрипторам. Если в образовании мы фиксируем уникальное во всех дескрипторах, мы обязаны признать, что эта система неповторима в целом среди других систем духовного производства, а следовательно, она уникальна.

\section{1 Литература}

[1] Блауберг И.В., Юдин Э.Г. Становление и сущность системного подхода. - М.: Наука, 1975.

[2] Пунченко О.П. Гносеологические основания философской критики. - Одесса: Астропринт, 2000.

[3] Уемов А., Сараева И., Цофнас А. Общая теория систем для гуманитариев / Под общ. ред. А.И. Уемова. - Варшава: Widawnictwo Universitas Rediviva, 2002.

[4] Уемов А.И. Системный подход и общая теория систем.-М.: Мысль, 1978.

[5] Цобнас А.Ю. Теория систем и теория познания.-Одесса: Астропринт, 1999. 